\title{
Effect of Functional Ingredients on Sensory Characteristics of Dairy Based Composite Sweet from Germinated Wheat Flour and Milk (Doda-Burfi)
}

\author{
Chawla Rekha $^{1}{ }^{*}$, Venus Bansal $^{2}$, Santosh Kumar Mishra ${ }^{3}$ and S. Sivakumar ${ }^{1}$ \\ ${ }^{1}$ Dairy Technology Division, Guru Angad Dev Veterinary and Animal Sciences University \\ (GADVASU), Ludhiana, 141004, Punjab, India \\ ${ }^{2}$ Dairy Technology Division, National Dairy Research Institute, Karnal-132001, India \\ ${ }^{3}$ Dairy Microbiology, Guru Angad Dev Veterinary and Animal Sciences University \\ Ludhiana, 141004, Punjab, India \\ *Corresponding author
}

\section{A B S T R A C T}

\begin{tabular}{|l|}
\hline Key w o r d s \\
Functional, \\
Composite sweet, \\
RSM, Sensory \\
acceptability, \\
Fiber, Optimization \\
\hline Article Info \\
\hline Accepted: \\
25 April 2017 \\
Available Online: \\
10 May 2017 \\
\hline \hline
\end{tabular}

Increasing demand for healthful and functional foods has given impetus to dairy processing industry especially traditional dairy product sector for development of tastier and healthier Indian sweetmeats. The objective of the present study was to develop functional doda-burfi supplemented with additional fiber and calcium fortification. The optimization was carried out using central composite rotatory design (CCRD) of response surface methodology (RSM). Effect of supplementation of oat fiber (1-3\%) and calcium $(50-100 \mathrm{mg} / 100 \mathrm{ml}$ of milk) was studied in doda burfi following standard recipe. Optimization was carried out using sensory responses. The sensory properties namely flavor, appearance, body and texture, mouth feel and overall acceptability of doda burfi samples were evaluated by a semi-trained panel of judges using 9-point hedonic scale. The results of the analysis showed that all the examined model solutions had significant influence on the different parameters indicating that the statistical model designed for these attributes fitted well in quadratic equation in all aspects of model efficiency check $\left(\mathrm{R}^{2}>0.80\right)$, except for color.

\section{Introduction}

In India, lifestyle related health problems like diabetes, obesity, hypertension and cardiovascular diseases are increasing at alarming rate (Lajolo, 2002). Change in the diet structure as work has become technological and involve no physical activity has led to two prolonged nutritional problems; one emerging from excesses and the other from the deficiency (Sharma and Garg, 2013). Thus, changing diet pattern, awaken awareness, and health consciousness among all the segments of population, and potential nutritional and therapeutic benefits associated with functional foods have led to the significant inclination towards these products. The hottest and vibrant results of functional foods has paved way towards the development of various functional foods with enhanced nutritional benefits using health promoting functional ingredients such as artificial sweeteners, dietary fiber, minerals and vitamins etc. The food industry views the functional foods as a business opportunity to cater this emerging health related to dilemma due to change in diet pattern. 
According to $\mathrm{WHO}$, it is estimated that up to 80 per cent of CHD, 90 per cent of type- 2 diabetes, and $1 / 3$ of cancers can be avoided by changing lifestyle, including diet. But dietary habits are notoriously difficult to change and even more difficult to sustain, even if the positive health effects are known. So nowadays, the area of research of nutritionists and food companies has shifted towards the enrichment of the conventional foods with the active ingredients. Several of these active ingredients are being incorporated into different variety of conventional foods to provide their health promoting effect with requiring behavioral changes (diet pattern, eating habits etc.) of consumers. Among various functional ingredients commercially available, phytosterols and dietary fibres have been used extensively in a variety of foods. Both of them have been associated with cholesterol lowering effects (Quilez et al., 2003; Delzenne et al., 2002).

Milk and milk products appear to be the almost complete foods excluding the source of dietary fiber. This attribute of milk products is particularly relevant when complementary diet does not support enough supply of dietary fiber. In this context, milk and milk products considered as a vehicle for dietary fibre would not only take care of their own role in human health but could also enhance the healthfulness of the diet as a whole (Patel and Arora, 2005). Addition of fiber and cholesterol lowering component in dairy products makes them enriched with dietary fiber along with lowering pressure for heart diseases and adds value to the product. High-fiber diets have been linked to reduce high serum cholesterol levels and various digestive disorders. Also, fiber not only increases the bulk of the food and moves it through the colon more rapidly, but also helps in preventing constipation and possible colon and rectal cancer (Niness, 1999; Thompson,
2005). Epidemiological studies correlating the high consumption of dietary fiber and lower incidence of certain diseases such as cardiovascular and cancer of colon and rectum, boosted searches on dietary fiber, several diseases such as diabetes, arthrosclerosis, breast cancer, diverticulitis, hemorrhoids, have been connected with a low intake fiber (Gutkoski et al., 2007) and high risk of obesity (Alfieri et al., 1995; Van Itallie, 1978).

Phytosterols have been used as blood cholesterol-lowering agents for the last half century (Peterson, 1951). They have been shown to be effective and safe. Originally presented as a pharmaceutical formulation (Pollak, 1953), phytosterols are now being added to an increasing variety of food stuffs. Pollak showed that plant sterols could reduce significantly plasma cholesterol levels in human beings. In addition to their cholesterol lowering effect, plant sterols may possess anti-cancer (Awad et al., 2003), antiatherosclerosis (Moghadasian et al., 1997), anti-inflammation (Bouic, 2001) and antioxidation activities (van Rensburg et al., 2000).

Though the conventional functional doda burfi contains good amount of fiber (6-7 per cent) in it, but to further enrich the product with dietary fiber, the study was planned in such a manner so that the extent of fairly acceptable fiber addition could be made. Keeping in mind, the development of functional doda burfi, various dietary fibers were chosen and screened on the basis of sensory evaluation. Further to increase the mineral content in the product, calcium fortification was also undertaken and extra benefits of lowering cholesterol was provided by addition of phytosterol. Thus, the objective of this investigation was to optimize the level of functional ingredients (fiber and calcium source) in functional doda burfi using 
response surface methodology. The aim of using advanced statistical approach was to prepare functional product with maximum consumer acceptability.

\section{Materials and Methods}

\section{Materials}

Fresh raw buffalo milk used for preparation of functional doda burfi was procured from Experimental dairy plant of National Dairy Research Institute, Karnal (Haryana), India, standardized to the desired Fat $(4.5 \%)$ and SNF (12\%) content. Oat fiber: Oat bran (30033) (Batch Number CA8 259) was procured from M/s S.A. Pharmachem Chemicals Limited, Mumbai (MH), India. Diesol ${ }^{\mathrm{TM}}$ (Hydrolyzed Gum acacia): Sample of hydrolyzed gum acacia (Batch Number 75060) available with a brand name Diesol ${ }^{\mathrm{TM}}$, was supplied by $\mathrm{M} / \mathrm{s}$ Drytech processes (I) Pvt. Ltd, Mumbai, India. For calcium fortification of milk, free sample of high grade tricalcium citrate (TCC) (Batch Number A09TCC0019) was supplied by M/s Sujata Chemicals, Baroda, Gujrat, India.

Free sample of phytostanol was supplied by M/s Raisio, Finland. To give the specific dark brown color to the product, food grade chocolate brown color (Ajanta brand) was obtained from the local market of Karnal (Haryana), India. High grade, sulphur free food grade crystalline table sugar was procured from the local market of Karnal (Haryana), India. To make up the SNF of the milk, fine quality roller dried skimmed milk powder (SMP) was procured from the experimental dairy plant of National Dairy Research Institute, Karnal (Haryana), India. All the chemical and reagents used for analysis were of AR grade.

\section{Preparation of functional doda burfi}

The manufacturing and analysis of functional doda burfi was carried out in the Experimental Dairy and Food Technology Lab, National Dairy Research Institute, Karnal. Functional doda burfi was prepared according to recipe and procedure given by Singh and Kumar (2006) with slight modifications. Milk was inoculated with dahi culture at the rate $1 \%$ (lactic culture), and after the development of acidity to $0.20 \%$ of lactic acid, germinated wheat flour (angoori atta) was added into it, and left undisturbed at room temperature for 1 to $1.5 \mathrm{hrs}$. The prepared slurry was cooked at slow flame until 3/ 4 moisture was removed. Sugar at the rate $18 \%$ was then added and the whole mixture was cooked quickly at high temperature $\left(85-90^{\circ} \mathrm{C}\right)$ with continuous stirring and scrapping the contents. At this stage, fiber, calcium and phytosterol were added in dissolved form and mixture was heated till a consistency where the product could attain a desired shape thereafter. On cooling, the product was garnished with nuts and cardamom and analyzed for its sensory profile. The prepared product was stable at ambient conditions for a period of 10-12 days without any signs of spoilage.

\section{Sensory evaluation}

The functional doda burfi was subjected to sensory evaluation by a panel of seven $(n=7)$ between the age of 35-55y from Dairy Processing Division of National Dairy Research Institute, Karnal, India. All the judges were trained sensory analysts, having a minimum of 15 years' experience in the sensory evaluation of milk and milk products. Nine-point hedonic scale was employed to carry out the evaluation of samples (Amerine et al., 1965) and total of five different attributes were generated pertaining to parameters which could fully describe the functional doda burfi were color, flavor, texture, sweetness and overall acceptability covering each and every parameter, 
completely describing the product. To eliminate the carry over effect, the samples were presented in random order. The sensory evaluation was carried out in individual booths under white light. Approximately $20 \mathrm{~g}$ of each sample was served at room temperature in petri dishes for evaluation of the product.

\section{Experimental design and statistical analysis}

The Central Composite Rotatable Design (CCRD) of Response Surface Methodology (RSM) was employed using quadratic model to setup the experimental design. The numbers of design points were obtained using statistical software package Design Expert ${ }^{\circledR}$ 6.0.10 (Stat Ease, Suite 480, 2021 East Hennepin Avenue, Minneapolis, USA) based on the numbers of independent variables. Two independent variables namely oat fiber (\%) and calcium salt (TCC) $(\mathrm{mg} / 100 \mathrm{ml})$ coded as $\mathrm{X}_{1}$ and $\mathrm{X}_{2}$ were chosen. Each independent variable had three levels which were $-1,0$ and +1 .

The second degree polynomial equation was used to describe the response (CanteriSchemin et al., 2005).

$$
y=\beta_{0}+\beta_{1} X_{1}+\beta_{2} X_{2}+\beta_{11} X_{1}^{2}+\beta_{22} X_{2}^{2}++\beta_{12} X_{1} X_{2}
$$

Where $\mathrm{y}=$ response; $\beta_{\mathrm{o}}=$ constant; $\beta_{1}, \beta_{2}=$ linear regression coefficients; $\beta_{11}, \beta_{22}=$ quadratic regression coefficients; $\beta_{12},=$ interaction regression coefficient; and $\mathrm{X}_{1}, \mathrm{X}_{2}$ $=$ variables

The level of ingredients used for design matrix for the experiments is presented in Table 1 while the experiment design with coded and actual values of variables is shown in Table 2. Before optimization, goals were set for each independent variable. The criteria for set up of goals were based on the sensory responses. All the responses were kept in range whereas overall acceptability was maximized. These parameters were decided so that an optimized product could be obtained with respect to sensory properties. The effect of different independent variables on the responses in presented in Table 3.

The analysis of variance (ANOVA) was conducted for each response to determine significant differences among various ingredients combinations. The effect of variables at linear, quadratic and interactive levels on individual response was described by computing the F-value at a probability (p) of 0.05 . The regression coefficients of individual linear, quadratic and interaction terms were also determined.

The optimization of the product was carried out on the basis of the desirability function. The optimized solution thus obtained was further validated by manufacturing functional doda burfi using optimized levels of independent variables. Mean values of three replicates were used for comparison. Student's t test was used to analyze significant difference between actual and predicted values.

\section{Results and Discussion}

\section{Flavor}

The flavor score of functional doda burfi ranged from 6.16 to 7.7 . Table 4 reveals that quadratic regression coefficient for both independent variables at quadratic level were positive though it was not significant $(p \geq 0.05)$. The negative correlation was observed at linear level of oat fiber and calcium salt however significant $(\mathrm{p} \leq 0.01)$ effect was observed with oat fiber only. It can be seen from Table 4 that interaction of oat fiber with calcium salt had positive effect on flavor though it was not significant 
statistically. Oat fiber and calcium salt had non-significant, though positive effect on the sensory sores of flavor. The probability value of 0.01 indicated that there was only $1.01 \%$ chances that Model "F-Value" could occur due to noise.

The three dimensional plots showing the effect of variables on flavor is shown in Fig. 1a. The negative effect of oat fiber and calcium salt is evident in the figure. The decrease in flavor score with increase of oat fiber possibly due to pronounced oats flavor while decrease in sensory score of flavor with increase in calcium salt might be due to increase in chalkiness. Kumar and Solanky (1997) also observed a similar trend in which there was a decrease in the flavor score of lassi with increase in stabilizer level. Addition of soluble fiber, inulin depicted the significant decreased flavor scores in direct acidified whey based lassi like beverage in the quadratic model (Nair and Thompkinson, 2008). Similar finding w.r.t. inulin (fiber) on the taste and aroma scores of fat-free yoghurt was reported by Guven et al., (2005), in which they observed a decrease in the flavor scores with increase in the concentration of inulin. In a similar manner, a slight decrease in flavor score with higher levels of guar gum was also observed and similar observations were recorded by Baines and Morris (1987) and Kumar and Tiwari (2005).

\section{Body and texture}

The experiment with $0.58 \%$ of oat fiber and $75 \mathrm{mg} / 100 \mathrm{ml}$ of calcium salt returned maximum response (8.26) while a minimum response (6.66) for sensory score of body and texture was observed with $3 \%$ oat fiber and $50 \mathrm{mg} / 100 \mathrm{ml}$ of calcium salt. The linear increase in oat fiber resulted in decrease of body and texture score of functional doda burfi and was highly significant $(\mathrm{p} \leq 0.01)$. Quadratic effect of oat fiber resulted in positive highly significant $(\mathrm{p} \leq 0.01)$ effect while the calcium salt showed insignificant ( $p \geq 0.05$ ) effect on body and texture scores of functional doda burfi. The interactive effect of oat fiber with calcium salt increased the body and texture score though it was nonsignificant $(p \geq 0.05)$. The chances in variation of Model F- value due to noise was only $0.03 \%$. Numerical value for the coefficient of determination $\left(\mathrm{R}^{2}\right)$ for obtained regression model was $94.55 \%$ which indicates a high significance of the model.

The decrease in sensory scores of body and texture at linear level of oat fiber could be due to water holding capacity and oil holding capacity of oat fiber. The decrease in body and texture score of functional doda burfi with an increase of oat fiber is evident in the Fig. 1b. Huang et al., (2011) also reported the decrease in body and texture of Chinese-style sausages with the increase of oat fiber content. The decrease in body and texture score at linear level while an increase in score at quadratic level was also reported by Singh et al., (2015) in the development of low-fat fiber-supplemented paneer. Similar findings were reported in poori preparation employing oat bran wherein significant $(p \leq 0.05)$ positive effect on moisture retention was observed (Yadav and Rajan, 2011).

\section{Color}

Table 4 reveals that the Model F-value for color was 1.32 which was lesser than the Tabulated F-value at 5\% level of confidence and hence non-significant. The coefficient of determination $\left(\mathrm{R}^{2}\right)$ was 0.48 which indicated there were only $48 \%$ chances that color was affected by the processing variables. However, adequate precision (4.28) being greater than 4 indicated an adequate signal and the model could be used to navigate the design space. 
Color scores of functional doda burfi ranged from 7.0-7.6 (Table 4). Model coefficients and $\mathrm{p}$ values showed that color scores of functional doda burfi was negatively correlated with oat fiber at linear and quadratic terms though it was insignificant $(p \geq 0.05)$. The decrease in sensory scores of color with an increase of oat fiber is evident in the Fig. 1c. It is noticed from the Table 4 that interactive effect of oat fiber with calcium salt had positive though nonsignificant $(\mathrm{p} \geq 0.05)$ effect on the sensory scores of color which is evident from the Fig. 1c. Calcium salt had insignificant $(p \geq 0.05)$ negative affect at linear terms while at quadratic level positive non-significant $(p \geq 0.05)$ effect on sensory scores of color was observed. The increase or decrease in color of the ultimate product can only be attributed to the little variation existing from batch to batch and had no correlation with the functional ingredients.

\section{Sweetness}

The sensory scores of sweetness obtained during the experiment were subjected to evaluation through quadratic model and the results of ANOVA regression analysis are represented in Table 4. The sweetness score of the resultant functional doda burfi varied from 6.83 to 7.7. Sensory scores of sweetness was found maximum at $1 \%$ oat fiber and 50 $\mathrm{mg} / 100 \mathrm{ml}$ of calcium salt while the minimum value was observed at $3 \%$ oat fiber and $50 \mathrm{mg} / 100 \mathrm{ml}$ of calcium salt. The coefficient of determination $\left(\mathrm{R}^{2}\right)$ was 0.86 which indicated that there were $86 \%$ chances that sweetness was affected by the processing variables. The lack of the fit test did not result in a significant F-value, indicating that the model was sufficiently accurate for predicting the sweetness made with any combination of factor levels within the range evaluated. The adequate precision (9.67) being greater than 4 indicated an adequate signal and could be used to navigate the design space.

It can be seen from Table 4 that oat fiber had highly significant $(\mathrm{p} \leq 0.01)$ negative effect on sweetness scores of functional doda burfi which is evident from Fig 1d that with the increase in amount of oat fiber sensory scores of sweetness decreases in a linear manner. Calcium salt also showed negative effect on the sensory scores of sweetness though it was not significant $(\mathrm{p} \geq 0.05)$. However, interactive effect of oat fiber with calcium showed positive effect on the sensory scores of functional doda burfi though it was non significant ( $\mathrm{p} \geq 0.05)$ statistically

\section{Overall acceptability}

The experimental results of the effect of oat fiber and calcium salt on the overall acceptability are shown in Table 4. The overall acceptability of the functional doda burfi varied from 6.56 to 7.54 . The maximum value of overall acceptability (7.54) was obtained for the product from $1 \%$ oat fiber and $50 \mathrm{mg} / 100 \mathrm{ml}$ of calcium salt while the experiment with $3 \%$ oat fiber and 50 $\mathrm{mg} / 100 \mathrm{ml}$ of calcium salt yields the minimum value of overall acceptability (6.56). The value of $\mathrm{P}_{\text {model }}$ was less than 0.05 , indicating that the model was significant at the probability level of 5\%. However, the lack of the fit test which is the variation of the data around the fitted model and measures the fitness of the model obtained did not result in a significant F-value, indicating that the model was sufficiently accurate for predicting the overall acceptability of functional doda burfi made with any combination of factor levels within the range evaluated.

Based on regression coefficients and ANOVA results, it was found that the levels of oat fiber and calcium salt at linear terms had a negative effect on the overall acceptability of functional doda burfi though significant 
$(p \leq 0.05)$ effect was observed with oat fiber only. Quadratic effect of oat fiber and calcium salt resulted in positive though no significant $(\mathrm{p} \geq 0.05)$ effect on the sensory scores of overall acceptability of functional doda burfi. The interactive effect of oat fiber with calcium salt increased the sensory scores of overall acceptability though the effect was non-significant ( $\mathrm{p} \geq 0.05)$. The $\mathrm{R}^{2}$ of the model was $83.0 \%$ which shows the high significance of the model. The three dimensional graphs shown in the Fig. 1e depicts that oat fiber had negative effect on the overall acceptability while the calcium salt initially decreased the score to certain point than increase in score was observed.

Table.1 Levels of ingredients used in central composite rotatable design for functional doda burfi

\begin{tabular}{lccc}
\hline & Lower limit & Upper limit \\
Variable & & level of ingredients & \\
& -1 & 0 & +1 \\
\hline Oat fiber $(\%)$ & 1 & 2 & 3 \\
Calcium $(\mathrm{mg} / 100 \mathrm{ml})$ & 50 & 75 & 100 \\
\hline
\end{tabular}

Table.2 The CCRD design for optimization experiments for developing functional doda burfi using response surface methodology

\begin{tabular}{ccccc}
\hline Run order & \multicolumn{2}{c}{ Coded values } & \multicolumn{2}{c}{ Un-coded values } \\
& Oat fiber & Calcium & Oat fiber $\%$ & $\begin{array}{c}\text { Calcium } \\
(\mathrm{mg} / 100 \mathrm{ml})\end{array}$ \\
\hline 1 & -1.414 & 0 & 0.59 & 75.00 \\
2 & 0 & -1.414 & 2.00 & 39.64 \\
3 & 0 & 0 & 2.00 & 75.00 \\
4 & 0 & 0 & 2.00 & 75.00 \\
5 & 1 & -1 & 3.00 & 50.00 \\
6 & 0 & 1.414 & 2.00 & 110.36 \\
7 & -1 & -1 & 1.00 & 50.00 \\
8 & 0 & 0 & 2.00 & 75.00 \\
9 & 1 & 1 & 3.00 & 100.00 \\
10 & -1 & 1 & 1.00 & 100.00 \\
11 & 0 & 0 & 2.00 & 75.00 \\
12 & 1.414 & 0 & 3.00 & 75.00 \\
13 & 0 & 0 & 2.00 & 75.00 \\
\hline
\end{tabular}


Table.3 Sensory attributes of functional doda burfi manufactured using functional ingredients $(n=7)$

\begin{tabular}{cccccccc}
\hline $\begin{array}{c}\text { Run } \\
\text { order }\end{array}$ & $\begin{array}{c}\text { Oat } \\
\text { fiber } \\
(\%)\end{array}$ & $\begin{array}{c}\text { Calcium } \\
(\mathrm{mg} / 100 \mathrm{ml})\end{array}$ & Flavour & Texture & Colour & Sweetness & $\begin{array}{c}\text { Overall } \\
\text { acceptability }\end{array}$ \\
1 & 1 & 50 & 7.5 & 8.21 & 7.3 & 7.7 & 7.54 \\
2 & 3 & 50 & 6.16 & 6.66 & 7.0 & 6.83 & 6.56 \\
3 & 1 & 100 & 7.42 & 7.96 & 7.0 & 7.6 & 7.46 \\
4 & 3 & 100 & 6.34 & 6.81 & 7.5 & 7.0 & 6.86 \\
5 & 0.59 & 75 & 7.7 & 8.26 & 7.3 & 7.5 & 7.4 \\
6 & 3.41 & 75 & 6.62 & 6.75 & 7.25 & 6.87 & 6.62 \\
7 & 2 & 39.64 & 7.2 & 7.3 & 7.3 & 7.5 & 7.3 \\
8 & 2 & 110.36 & 7.0 & 7.1 & 7.6 & 7.1 & 6.78 \\
9 & 2 & 75 & 7.18 & 6.83 & 7.16 & 7.16 & 6.83 \\
10 & 2 & 75 & 6.85 & 6.9 & 7.5 & 7.2 & 6.9 \\
11 & 2 & 75 & 7.0 & 7.0 & 7.5 & 7.0 & 7.0 \\
12 & 2 & 75 & 6.8 & 7.3 & 7.3 & 7.1 & 6.74 \\
13 & 2 & 75 & 6.81 & 7.16 & 7.0 & 7.0 & 6.67 \\
& & & & & & & \\
\hline
\end{tabular}

Table.4 Coefficient of full second order polynomial model for sensory responses of functional doda burfi

\begin{tabular}{|c|c|c|c|c|c|}
\hline Factor & Flavour & Texture & Colour & Sweetness & $\begin{array}{l}\text { Overall } \\
\text { acceptability }\end{array}$ \\
\hline Intercept & 8.71 & 10.83 & 8.36 & 9.51 & 9.83 \\
\hline A- oat fiber & $-0.87 * *$ & $-1.89 * *$ & -0.38 & $-0.72 * *$ & $-1.06 * *$ \\
\hline $\begin{array}{l}\text { B-calcium } \\
(\mathrm{mg} / 100 \mathrm{ml})\end{array}$ & -0.01 & -0.03 & -0.02 & -0.03 & -0.04 \\
\hline$A * B$ & 0.002 & 0.003 & 0.008 & 0.002 & 0.003 \\
\hline$A^{2}$ & 0.048 & $0.247 * *$ & -0.04 & 0.056 & 0.11 \\
\hline $\mathrm{B}^{2}$ & 0.00002 & 0.0001 & 0.00006 & 0.0001 & 0.0002 \\
\hline $\mathrm{R}^{2}$ & 0.84 & 0.95 & 0.48 & 0.86 & 0.83 \\
\hline Lack of fit & $3.40^{\mathrm{ns}}$ & $0.45^{\mathrm{ns}}$ & $0.49^{\mathrm{ns}}$ & $3.72^{\mathrm{ns}}$ & $3.04^{\mathrm{ns}}$ \\
\hline $\begin{array}{l}\text { Adequate } \\
\text { precision }\end{array}$ & 8.86 & 15.03 & 4.28 & 9.67 & 8.09 \\
\hline Model 'F'value & $7.40 *$ & $24.53 * *$ & 1.32 & $9.07 * *$ & $7.17 *$ \\
\hline
\end{tabular}


Table.5 Goals set for constraints to optimize the technology of functional doda burfi

\begin{tabular}{lcccccc}
\hline $\begin{array}{c}\text { Constraints } \\
\text { name }\end{array}$ & $\begin{array}{c}\text { Goal set for } \\
\text { optimized product }\end{array}$ & Lower limit & Upper limit & $\begin{array}{c}\text { Lower } \\
\text { weight }\end{array}$ & $\begin{array}{c}\text { Upper } \\
\text { weight }\end{array}$ & Importance \\
\hline Oat fiber & is in range & 1 & 3.0 & 1 & 1 & 3 \\
Calcium & is in range & 50 & 100 & 1 & 1 & 3 \\
Colour & is in range & 7.3 & 7.6 & 1 & 1 & 3 \\
Texture & is in range & 8.0 & 8.26 & 1 & 1 & 3 \\
Sweetness & is in range & 7.3 & 7.70 & 1 & 1 & 3 \\
Flavour & is in range & 7.2 & 7.70 & 1 & 1 & 3 \\
OAA & Maximize & 7.2 & 7.54 & 1 & 1 & 3 \\
\hline
\end{tabular}

Fig.1a\&b Effect of oat fiber and calcium on flavor and texture scores of functional doda burfi
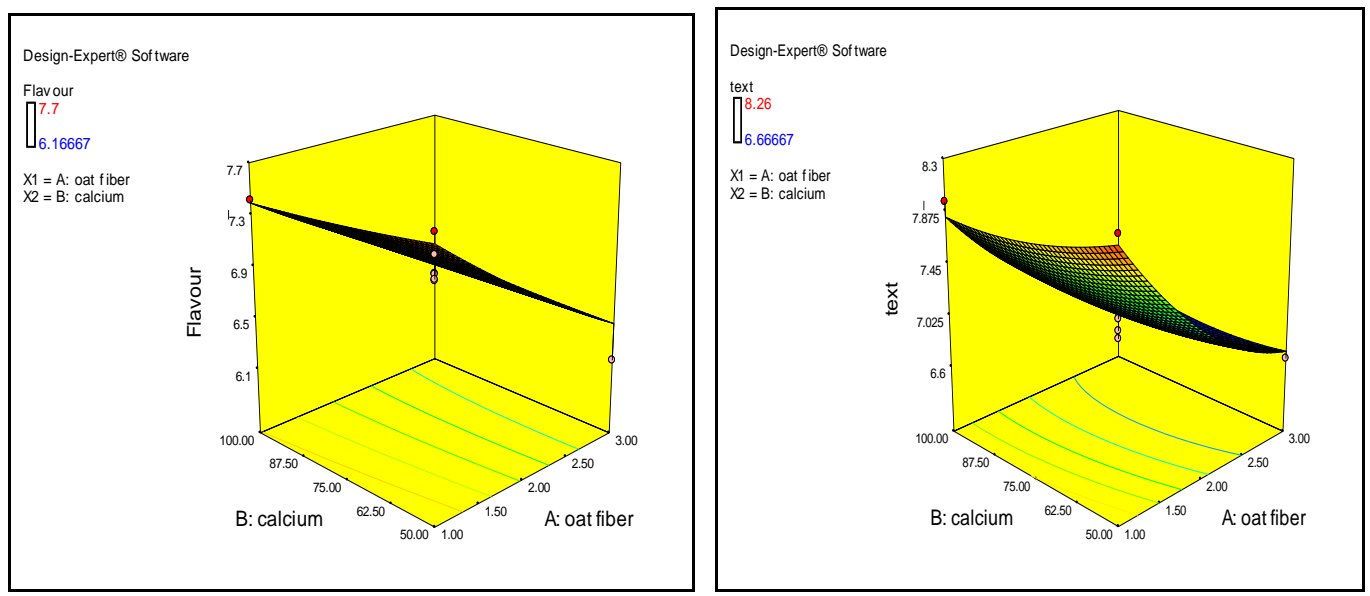

Fig.1c\&d Effect of oat fiber and calcium on colour and sweetness scores of functional doda burfi
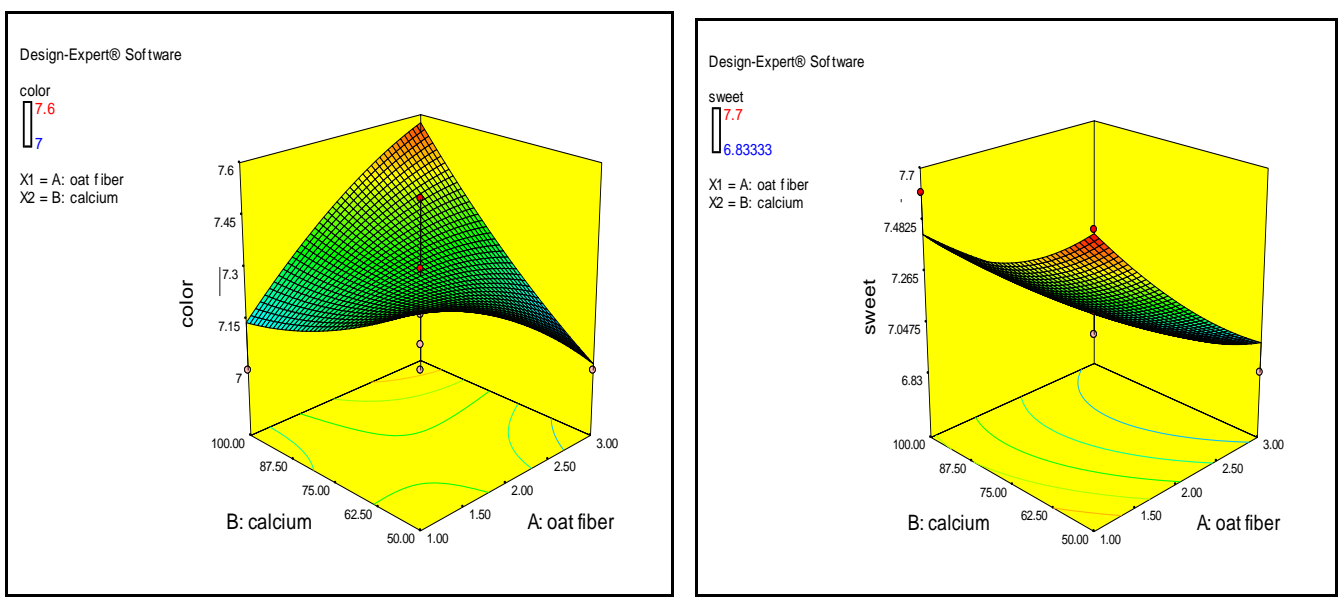
Int.J.Curr.Microbiol.App.Sci (2017) 6(5): 2385-2398

Table.6 Eight suggested solutions vide RSM design for optimum combinations of oat fiber and calcium

\begin{tabular}{lccccccccc}
\hline $\begin{array}{l}\text { Solutions } \\
\text { number }\end{array}$ & Oat Fiber & Calcium & Colour & Texture & Sweetness & Flavour & OAA & Desirability \\
\hline 1 & 1.01 & 50.40 & 7.383 & 8.114 & 7.675 & 7.563 & 7.545 & 1.00 \\
2 & 1.00 & 50.67 & 7.381 & 8.118 & 7.674 & 7.566 & 7.545 & 1.00 \\
3 & 1.01 & 50.02 & 7.386 & 8.125 & 7.683 & 7.568 & 7.554 & 7.00 \\
4 & 1.02 & 50.36 & 7.382 & 8.104 & 7.671 & 7.558 & 7.540 & 7.554 & 1.00 \\
5 & 1.00 & 50.24 & 7.385 & 8.128 & 7.682 & 7.570 & 7.545 & 1.00 \\
6 & 1.02 & 50.16 & 7.384 & 8.111 & 7.676 & 7.561 & 7.543 & \\
7 & 1.02 & 50.02 & 7.384 & 8.104 & 7.674 & 7.557 & 7.00 \\
8 & 1.00 & 52.31 & 7.369 & 8.102 & 7.654 & 7.561 & 7.521 & 0.947 \\
\hline
\end{tabular}


Table.7 Characteristics of the developed functional optimized product ( $\mathrm{n}=3$ )

\begin{tabular}{llc}
\hline Property & \multicolumn{1}{c}{ Attribute } & Value \\
Sensory & Colour and appearance & $7.66 \pm 0.04$ \\
& Texture & $7.58 \pm 0.24$ \\
& Sweetness & $7.00 \pm 0.91$ \\
& Flavour & $7.75 \pm 0.04$ \\
& Overall acceptability & $7.25 \pm 0.05$ \\
Physico-chemical & IDF & $8.47 \pm 1.47$ \\
& SDF & $6.25 \pm 1.25$ \\
& Calcium & $62.32 \pm 0.11$ \\
Textural attributes & Iron & $3.40 \pm 0.005$ \\
& Hardness (N) & $46.03 \pm 3.41$ \\
& Adhesiveness (N.s) & $-2.69 \pm 0.33$ \\
& Springiness & $0.338 \pm 0.08$ \\
& Cohesiveness & $0.191 \pm 0.009$ \\
Instrumental & Gumminess (N) & $8.81 \pm 0.98$ \\
colour values & Chewiness (N) & $2.94 \pm 0.53$ \\
& Lightness (L*) & $33.40 \pm 0.05$ \\
Microbiological & Redness (a*) & $14.90 \pm 0.04$ \\
count & Yellowness (b*) & $23.17 \pm 0.09$ \\
& Standard plate count & $2 \mathrm{X} 10^{2}$ \\
& Yeast and mould count & $5 \mathrm{X} 10^{3}$ \\
& Coliform count & nil \\
\hline
\end{tabular}

Fig.1e Effect of oat fiber and calcium on overall acceptability score of functional doda burfi

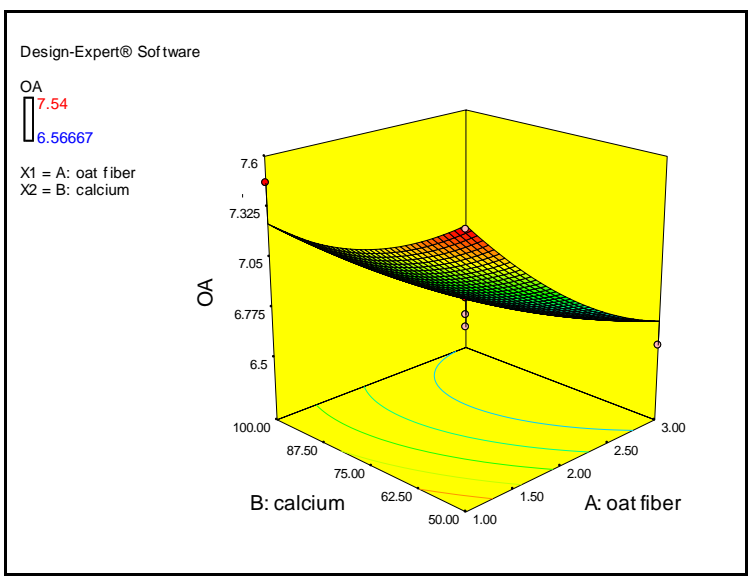


Fig.2 Sensory evaluation results of functional product having varying percentage of phytostanol

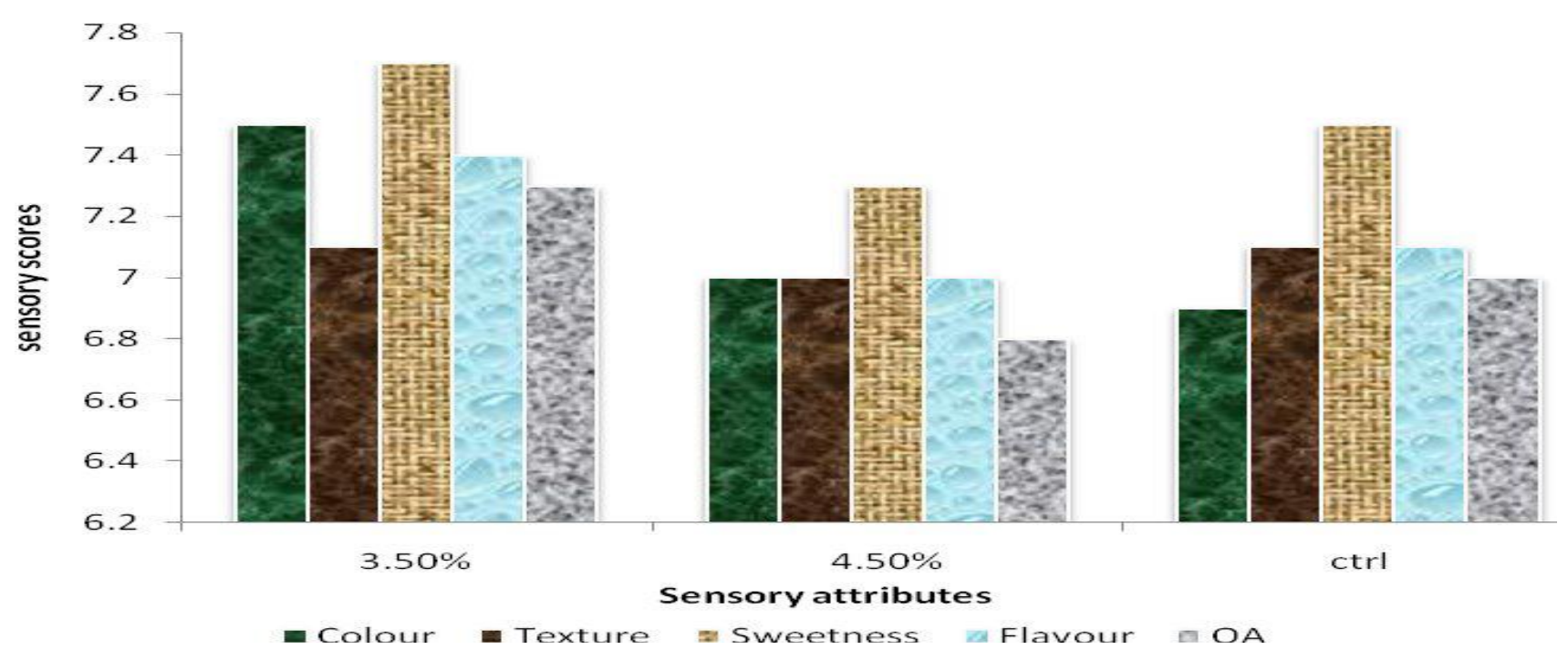

Similarly, based on some previous studies, two different levels of phytostanol were tried with the final recipe of functional doda burfi. The levels worked upon were $3.5 \%$ and $4.5 \%$ and the results were compared with control sample with zero or no added phytostanol in it. To select the best optimal level of phytostanol, product was evaluated by a panel of semi trained judges using a 9-point hedonic scale for sensory attributes and the results have been presented in Fig. 2. It can be observed from the Fig 2 that the sensory scores of functional doda burfi increased with the addition of phytostanol @ 3.5\% except body and texture score when compared with the control sample. Increase in color and appearance score may be due to shinier appearance of the product with the addition of phytostanol. Phytostanols, being non-polar in nature apart from performing the action of lowering the cholesterol also provided shinier appearance to the product. The maximum overall acceptability of composite cereal-milk based sweet was observed with $3.5 \%$ phytostanol when compared with control and the product with $4.5 \%$ phytostanol (Fig. 2). On the basis of the results obtained, 3.5\% phytostanol was adjudged the best level to be used for the development of functional cerealmilk composite sweet.

In conclusion, functional composite cerealmilk based sweet was successfully prepared with view to make it suitable for health conscious segment. Response surface methodology was well suited for evaluating the individual and interaction effect of variables on sensory characteristics of functional cereal-milk based composite sweet. Developed product was found to have similar product characteristics and overall acceptability when compared with the conventional product.

\section{References}

Alfieri, M.A., Pomerleau, J., Grace, D.M., and Anderson, L. 1995. Fiber intake of normal weight, moderately obese and severely obese subjects. Obese Res., 3: 541-547.

Amerine, M.A., Pangborn, R.M., and Roessler, E.B. 1965. Principals of sensory valuation of Food. New York: Academic Press.

Awad, A.B., Roy, R., and Fink, C.S. 2003.Beta-sitosterol, a plant sterol, 
induces apoptosis and activates key caspases in MDA-MB-231 human breast cancer cells. Oncol. Rep., 10: $497-500$

Baines Z.V., and Morris, E.R. 1987. Flavor/taste perception in thickened systems: The effect of guar gum above and below C. Food Hydrocoll., 1: 197205.

Bouic, P.J. 2001.The role of phytosterols and phytosterolins in immune modulation: a review of the past 10 years. Curr. Opin. Clin. Nutr. Metab. Care, 4: 471-475.

Canteri-Schemin, M.H., Fertonani, H.C.R., Waszczynskyj, N., and Wosiacki, G. 2005. Extraction of pectin from apple pomace. Braz. Arch. Biol. Technol., 48: 259-266.

Delzenne, N., Daubioul, C., Neyrinck, M., Lasa, M., and Taper, H.S. 2002. Inulin and oligofructose modulate lipid metabolism in animals: review of biochemical events and future prospects. British J. Nutr., 87: S255S259.

Gutkoski, L.C., de Bonamigo J.M.A., de Teixeira D.M.F., and Pedo, I. 2007. Development of oat based cereal bars with high dietary fiber content. Ciencia $e$ Tecnologia de Alimentos, 27: 355363.

Guven, M., Yasar, K., Karaca, O.B., and Hayaloglu, A.A. 2005. The effect of inulin as a fat replacer on the quality of set type low-fat yoghurt manufacture. Inter. J. Dairy Technol., 58: 180-184.

Huang, S.C., Tsai, Y.F., Chen, C.M. 2011. Effects of wheat fiber, oat fiber, and inulin on sensory and physico-chemical properties of Chinese-style sausages. Asian-Aust. J. Animal Sci., 24: 875-880.

Kumar, A., and Solanky, M.J. 1997. Influence of stabilizers on sensory quality of lassi. Ind. J. Dairy Sci., 50: 250-253.

Kumar, A., and Tiwari, B.D. 2005. Preparation of whey based milk drink.
Ind. J. Dairy Sci., 58: 321-325.

Lajolo, M.F. 2002. Functional foods: Latin American Perspectives. British $J$. Nutrition, 88: S145-S150.

Moghadasian, M.H., McManus, B.M., Pritchard, P.H., and Frohlich, J.J. 1997. "Tall oil"- derived phytosterols reduce atherosclerosis in ApoE-deficient mice. Arterioscler Thromb. Vasc. Biol., 17: 119-126.

Nair, K., and Thompkinson, D.K. 2008. Optimization of ingredients for the formulation of a direct acidified whey based lassi-like beverage. Inter. J. Dairy Technol., 61: 199-205.

Niness, K. 1999. Breakfast foods and the health benefits of inulin and oligofructose. Cereal Foods World, 44: 79-81.

Normen, L., Dutta, P., Lia, A., and Andersson, H. 2000. Soy sterol esters and $\beta$-sitostanol ester as inhibitors of cholesterol absorption in human small bowel. Americ. J. Clinic Nutri., 71: 908913.

Patel, A.A., and Arora, S.K. 2005. Fiber fortification of dairy products. In Proceedings of the National Seminar on Value Added Dairy Products held at National Dairy Research Institute, Karnal, p 21-22.

Peterson, D.W. 1951. Effect of soybean sterols in the diet on plasma and liver cholesterol in chicks. Proc. Soc. Exp. Biol. Med., 78: 143-147.

Pollak, O.J. 1953. Reduction of blood cholesterol in man. Circulation, 7: 702706.

Quilez, J., Garcia-Lorda, J.,and SalasSalvado.2003. Potential uses and benefits of phytosterols in diet: present situation and future directions. Clin Nutr., 22: 343-351.

Sharma, M., and Garg, S. 2013. Functional foods: Marketing 'Health' to modern 
India. Int. J. Innov. Res. Develop., 2: 120.

Singh, A.K., and Kumar, A. 2006. Technology of selected region specific milk products. In: $21^{\text {st }}$ Short course on Developments in traditional dairy products, Dec. 10-30, 2006, Karnal. pp 225-234.

Singh, G., Kumar, A., Kumbhar, B.K., and Dar, B.N. 2015. Optimization of processing parameters and ingredients for development of low-fat fibresupplemented paneer. J. Food Sci. Tech., 52: 709-719.

Thompson, P. 2005. White breads can also be high fiber. Wellness Foods Euro., 34: 30-33.

Van-Itallie, T.B. 1978. Dietary fiber and obesity. Americ. J. Clinic Nutri., 31: S43-52.
Van-Rensburg, S.J., Daniels, W.M., Van-Zyl, J.M., and Taljaard, J.J. 2000. A comparative study of the effects of cholesterol, beta-sitosterol, betasitosterolglucoside, dehydroepiandro-steronesulphate and melatonin on in-vitro lipid peroxidation. Metab Brain Dis., 15: 257-265.

Weststrate, J.A, and Meijer, G.W. 1998. Plant sterol-enriched margarines and reduction of plasma total-and LDLcholesterol concentrations in normocholesterolaemic and mildly hypercholesterolaemic subjects. Euro J. Clinic Nutri., 52: 334-343.

Yadav, D.N., and Rajan, A. 2011. Fibres as an additive for oil reduction in deep fat fried poori. J. Food Sci. Tech., 49(6): 767-773.

\section{How to cite this article:}

Chawla Rekha, Venus Bansal, Santosh Kumar Mishra, Sivakumar, S. 2017. Effect of Functional Ingredients on Sensory Characteristics of Dairy Based Composite Sweet from Germinated Wheat Flour and Milk (Doda-Burfi). Int.J.Curr.Microbiol.App.Sci. 6(5): 23852398. doi: https://doi.org/10.20546/ijcmas.2017.605.267 